\title{
FAILURE OF MAGNETIC FLUID SEALS OPERATING IN WATER: PRELIMINARY CONCLUSIONS
}

Leszek Matuszewski

Gdansk University of Technology, Poland

\begin{abstract}
The article analyses properties of magnetic fluid seals installed in rotary sealing nodes which operate in the utility water environment. Seals of this type have been examined as a possible solution to the problem with ship manoeuvring propulsion sealing. The present analysis bases on laboratory durability tests of magnetic fluid seals exposed to longterm utility water loads, at different water pressures and shaft revolutions. The basic seal durability criterion was the number of revolutions made by the sealing node shaft until the appearance of water tightness loss (leakage). It was found that the main factor leading to the wear of the seal is the relative speed of the magnetic fluid with respect to that of the utility water, and this process is heavily affected by the pressure acting on the seal. The reported test results are presented in the form of diagrams showing the seal durability (time until water tightness loss) as a function of rotational speed. The curves shown in the diagrams are regular, with two different rotational speed ranges: the highspeed range, when the tightness loss is relatively fast, and the low-speed range, with a clear tendency to prolong the seal lifetime. These diagrams were given the name of durability curves of the MF seal operating in water. The results of the performed tests suggest formal similarity between the experimental data distribution concerning tightness loss processes occurring in magnetic fluid seals operating in water environment and metal fatigue processes. The article proposes a preliminary simplified durability model to describe the examined phenomenon.
\end{abstract}

Keywords: seal, magnetic fluid

\section{INTRODUCTION}

Rotary magnetic fluid (MF) seals have been successfully used for years in gas environments or in vacuum conditions, when extremely high tightness was to be ensured at very small resistance of the sealing node $[11,15]$. The correctly designed MF seal should have the magnetic system and the shape of sealing teeth arranged in such a way that the magnetic field is concentrated in a small gap. The maximum value of magnetic induction generated in this area keeps permanently the magnetic fluid in the gap, until the critical pressure is exceeded. As long as the gas pressure is lower than the critical pressure, the action of the gas environment on the magnetic fluid surface is small and in these conditions the seal can work for many years without tightness loss. In this case the seal lifetime is affected by physicochemical processes taking place inside the fluid which decrease its saturation magnetisation and, as a consequence, its critical pressure.
The situation changes dramatically when the magnetic fluid seal operates in liquid environment [9]. A basic condition for correct operation of the seal in water environment is the appearance of strong water repellent effect on the interface between the magnetic fluid and the sealed fluid to prevent these two fluids from mixing. To achieve this effect, the selected magnetic fluid should have properties adequate to those of the environmental fluid to ensure high interface tension.

If the seal is used in the fluid environment in static conditions, the magnetic field acting to keep the magnetic fluid within a given space and high interface tension should be sufficient to ensure long-term tightness. By contrast, in the rotary MF seal, in which the magnetic fluid comes into direct contact with the sealed environmental fluid, both the action of the magnetic field on the magnetic fluid and the hydrodynamic action of the interface between the sealing and environmental fluids take place. The direction and value of the magnetic field and the relative magnetic fluid/ 
environmental fluid velocity vector affect significantly the stability of the interface and the resultant durability of the seal. These issues are the object of theoretical analyses published in scientific and technical literature [14]. The experimental research publications [8] on magnetic fluid seals working in liquid environments confirm the effect of the magnetic field and interface stability on the seal's lifetime.

In the examined MF seals, the dominating magnetic field strength direction within the magnetic fluid area is radial, whereby in the vicinity of the water/magnetic fluid interface the component perpendicular to the interface is also observed. This magnetic field distribution is used in well-known designs of rotary seals $[4,9,10]$, as it provides maximal values of critical pressure in the seal and is relatively simple to execute.

Magnetic field distribution in the seal is not the object of examination in this paper.

For many years, the Faculty of Mechanical Engineering and Robotics, AGH University of Science and Technology, Cracow, in collaboration with Gdansk University of Technology, have examined MF seals working in the utility water environment. Among other goals, the research aimed at assessing the applicability of MF seals in ship propulsion systems $[7,16,17,18]$. This article makes use of part of the results obtained within the framework of the NCRD research project [13], studying the effect of relative velocity between environmental fluid and magnetic fluid on seal durability. The performed research was extremely time-consuming, as it mainly concerned the long-term seal durability as a function of the magnetic fluid velocity with respect to the environmental fluid at different pressures acting on the seal. The objects of examination were seals with one and many sealing teeth.

The article presents the course and results of examination of a sealing sleeve with three teeth. Consecutive paper chapters describe the examined sealing system and the used examination procedures, and present typical durability curves obtained for three types of examined magnetic fluids. Basic information and definitions of the used quantities and research terms are included. An attempt is made to generalise the process of wear of the MF seal working in water by applying the mathematical model of durability based on fatigue models presented in [3]. Finally, conclusions resulting from the performed research are presented.

It is noteworthy that, to the author's knowledge, this is the first systematic approach to the problem of long-term durability of a MF seal working in liquid environment.

The need to perform a large number of time-consuming tests was the reason why the collected experimental data stock is relatively small. The author is aware of the fact that some conclusions may seem controversial and require further targeted research and analyses oriented on their thorough verification.

\section{THE EXAMINED SEAL SYSTEM AND SAMPLE DURABILITY CURVES}

The tests were performed on the research rig described in detail in [6], which also provides descriptions of research assumptions and applied procedures. To facilitate understanding of the issues being the object of this research, Fig. 1 presents one version of the research node and explains basic terms used in the experiment and analyses. The figure shows the test system used for examining the MF seal with three teeth, and the dimensions of main system components, which are: driving shaft with sealing sleeve, nose cap and centrifugal discs rotating against stationary elements, and the magnetic arrangement consisting of permanent magnet discs, magnetic poles, nonmagnetic ring and intermediate plate with pressure measurement channel.

The utility water used in the tests was supplied to the water chamber at a pre-set pressure. The nose cap and the intermediate plate were used to ensure the required homogeneity of the water flow in the vicinity of the magnetic seal interface (see also details 2:1 and 20:1 in the figure). After the seal failure, the water penetrated in the leakage direction (shown in figure), then approached the centrifugal discs where it leaved the system and flowed to the leakage detection device (not shown).

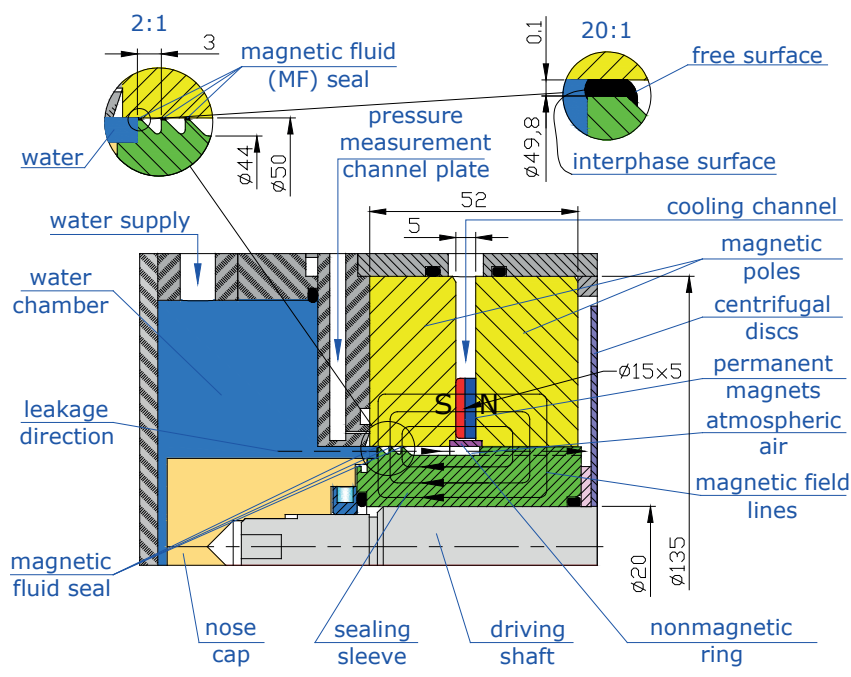

Fig.1. The examined MF sealing system with three teeth.

The magnetic fluids used in the experiment were produced by the Russian company Ferrolabs [2]. Table 1 collates physical properties of the examined fluids and their typical technical applications.

The magnetic field was generated by a set of permanent magnets in the form of $ø 15 \times 5 \mathrm{~mm}$ disks having the following characteristics [12]:

Magnetic material:

Residual magnetic induction:

Neodym N38

$\mathrm{B}_{\mathrm{r}}=1,23 \mathrm{~T}$

Commercial strength:

Maximal energy density:

Maximal operating temperature:
$\mathrm{H}_{\mathrm{c}}=912 \mathrm{kA} / \mathrm{m}$

$(\mathrm{BH})_{\max }=294 \mathrm{~kJ} / \mathrm{m}^{3}$ $150{ }^{\circ} \mathrm{C}$ 
The pole shoes and the sleeves with sealing teeth were made of low-carbon steel with relative magnetic permeability $\mu_{\mathrm{r}}>2000$.

Tab.1 Basic parameters of the examined ferromagnetic fluids [4]

\begin{tabular}{|c|c|c|c|}
\hline \multirow{2}{*}{ PARAMETER: } & \multicolumn{3}{|c|}{ Type of fluid } \\
\hline & FLS 040.040 & FLA002.25 & FLA003.45 \\
\hline Type of carrier fluid: & Silicone fluid & Siloxane & Siloxane \\
\hline Saturation magnetisation, $\mathrm{kA} / \mathrm{m}$ & $40 \div 50$ & 25 & 45 \\
\hline Operating temperature, ${ }^{\circ} \mathrm{C}$ & -70 do 150 & -70 do 150 & -70 do 150 \\
\hline Critical temperature, ${ }^{\circ} \mathrm{C}$ & 200 & 250 & 200 \\
\hline Freezing point, ${ }^{\circ} \mathrm{C}$ & -100 & No data & No data \\
\hline Plastic viscosity in $27^{\circ} \mathrm{C}$ & $300-800 \mathrm{~Pa} \cdot \mathrm{s}$ & $700-750 \mathrm{mPa} \cdot \mathrm{s}$ & $400-500 \mathrm{mPa} \cdot \mathrm{s}$ \\
\hline Colour of liquid: & black-brown & black-brown & black-brown \\
\hline Evaporation coefficient, $g \cdot S m^{-2} c^{-1}$ & No data & & \\
\hline Thermal conductivity in $38^{\circ} \mathrm{C}, \mathrm{mWt} / \mathrm{m} \cdot \mathrm{K}$ & No data & 150 & 150 \\
\hline Applications: & $\begin{array}{l}\text { High rotational speeds, } \\
\text { food and pharmaceutical } \\
\text { industries }\end{array}$ & $\begin{array}{l}\text { Midranges, tweeters, and } \\
\text { buzzers }\end{array}$ & Woofers and buzzers \\
\hline
\end{tabular}

Figures 2, 3 and 4 [13] show sample results of durability examination of seals with magnetic fluids given in Table 1. The results are presented in the form of points with research coordinates and a curve presenting the trend of the point distribution.

Basic quantities used in the descriptions of diagrams in the figures are defined as follows:

Critical pressure $\left(\boldsymbol{p}_{k r}\right), \mathrm{MPa}$ is the highest pressure which does not lead to leakage through the seal in static conditions.

Operating pressure $\left(\boldsymbol{p}_{r}\right), \mathrm{MPa}$ is the water pressure which is set and kept constant during the seal durability test.

Critical velocity $\left(\boldsymbol{n}_{k r}\right), \sec ^{-1}$ is the lowest rotational speed of the seal at which the leakage is observed after a period no longer than $20 \mathrm{~s}$ from the beginning of examination.

Boundary velocity $\left(\boldsymbol{n}_{g r}\right), \sec ^{-1}$ is the rotational speed of the seal which divides the trend line into two parts with different durability gradients.

Seal durability $(t), \mathrm{s}$ is the time of seal operation until leakage.

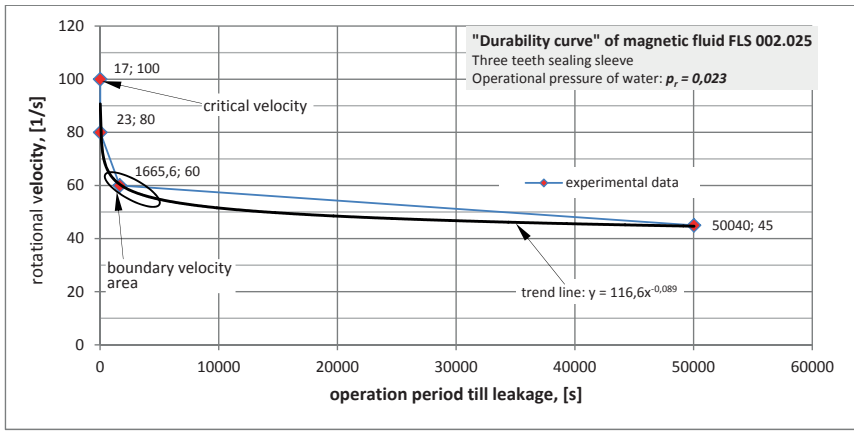

Fig. 2. Durability of seal with magnetic fluid FLS 002.025 in contact with water vs. rotational speed of sealing sleeve. The sealing system is shown in Fig.1

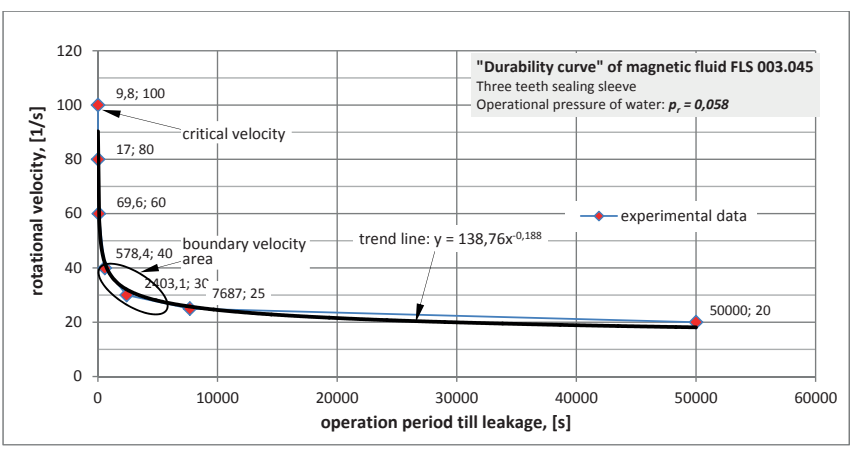

Fig. 3. Durability of seal with magnetic fluid FLS 003.045 in contact with water vs. rotational speed of sealing sleeve. The sealing system is shown in Fig. 1

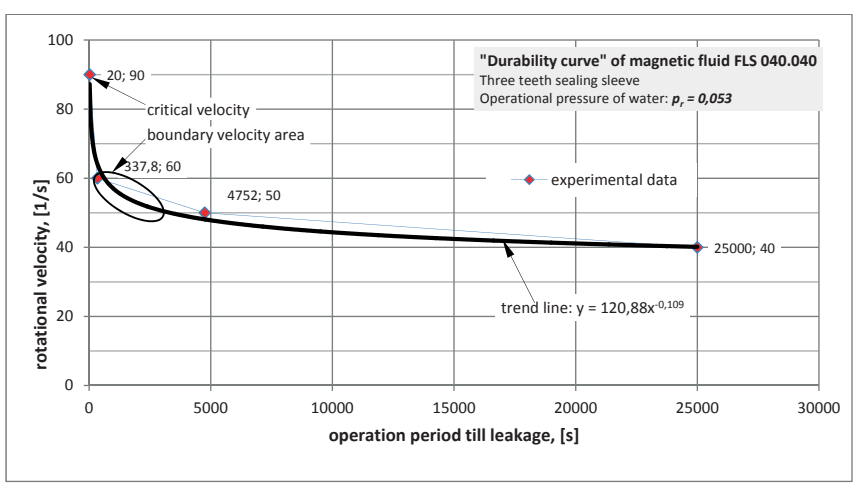

Fig. 4. Durability of seal with magnetic fluid FLS 040.040 in contact with water $v$ s. rotational speed of sealing sleeve. The sealing system is shown in Fig.1FLS 040.040. $\mathrm{p}_{\mathrm{r}}=0,053$

The testing procedure assumed performing successive tests for gradually decreasing rotational speed until the level at which the seal made over 1 million revolutions without leakage was achieved. In this context, the time of seal operation with lowest rotational speed means that the seal durability at this speed is higher than that shown in the diagram. 
The tests were performed at different water pressures in the sealing system. Along with the magnetic fluid velocity, the pressure is the other key factor affecting the operating durability of the seal.

The presented diagrams are representative of large majority of the performed tests. In each diagram, the high-speed range can be found in which the seal is damaged after the time ranging from slightly more than ten seconds to a dozen or so minutes, and the low speed range in which the seal is damaged after the time between several and more than ten hours of continuous operation. Between those two ranges, a transitional range is observed in which the boundary velocity is situated. The definition of the boundary velocity is not precise because this velocity can depend on many factors which are difficult to clarify at this research stage.

An opinion can be found in the scientific literature [2, $8,12]$ that the boundary velocity can be related to interface instability which appears at certain velocity difference between the contacting fluids.

\section{MATHEMATICAL MODEL OF MF SEAL DURABILITY}

The mathematical model of durability of the seal with magnetic fluid has been developed based on the available experimental data [13] obtained in the seal durability tests described in Section 2. More than 60 tests were performed. Their duration times ranged from a dozen or so seconds to over 30 hours of continuous operation. The tests differed by rotational speed of the seal, set within the range from $1 \mathrm{rev} / \mathrm{s}$ to $100 \mathrm{rev} / \mathrm{s}$, and by water environment pressure, ranging from $0,023 \mathrm{MPa}$ to $0,174 \mathrm{MPa}$. Both parameters were kept constant during one test.

As mentioned in the previous section, the experimental data distributions were similar to each other in large majority of tests, with clearly distinctive high and low speed durability ranges, separated by the transitional range in which the hypothetical boundary velocity was situated.

What was noteworthy was formal similarity of the experimental data recorded for the examined seals in the $\mathrm{n}$ - $\mathrm{t}$ coordinate system (where $\mathrm{n}$ is the rotational speed of the magnetic fluid in the seal, $\mathrm{s}^{-1}$; and $\mathrm{t}$ is the time of seal operation until leakage) with fatigue characteristics of steel in the $\sigma-\mathrm{N}$ coordinate system (where $\sigma$ is stress, $\mathrm{MPa}$; and $\mathrm{N}$ is the number of fatigue cycles). In both cases a characteristic quantity can be observed which refers to immediate damage of the examined object. For the seal leakage phenomenon, it is the boundary velocity of the seal (leakage after less than 20 seconds), while for the fatigue analysis it is the immediate strength of steel sample (damage in the $1 / 4$-cycle test). In both cases a boundary value can be found which separates the limited durability range and the long-term operation range. In the former and latter case, respectively, this role is played by the boundary velocity of the seal and the fatigue strength limit of steel sample.
Being well aware that the physics of these two phenomena is completely different, a decision was made to search for the mathematical model of durability of the examined seal within relatively well-developed metal fatigue models.

Gasiak and Pawliczek [8] presented fatigue characteristics for low-alloy structural steels. They also proposed a formula describing the relation between the variable stress amplitude limit and the number of cycles $\mathrm{N}$ for different average stress values in the cycle [3]. Assuming that the effect of the average stress value on its amplitude is linear, the fatigue surface formula takes the following form:

$$
\sigma_{a}\left(N, \sigma_{m}\right)=\left(\frac{z_{G}^{m} N_{0}}{N}\right)^{1 / m}-\eta N^{\lambda} \sigma_{m}
$$

where:

$m$ - fatigue line slope within the limited fatigue strength range (material constant),

$Z_{G} \quad$ - material fatigue limit (material constant), $N_{0} \quad$ - limiting number of cycles (material constant), $\eta, \lambda$ - equation coefficients.

The shape of the fatigue surface obtained from formula (1) is shown in Fig.5.

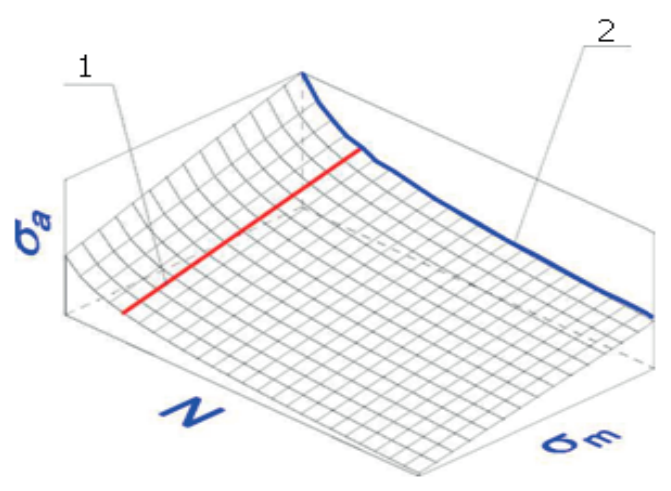

Fig. 5 Limiting surface of variable stress amplitudes as function of the number of cycles $N$ and the average stress value $\sigma_{m}, \sigma_{a}=f\left(N, \sigma_{m}\right)$. Curves 1 and 2 show trends of $\sigma_{a}$ changes in $N$ and $\sigma_{m}$ directions [ 7 and 8].

For the purposes of magnetic fluid seal durability model development, the experimental data concerning the examined seals have been arranged in the $v-N$ coordinate system, where $v, \mathrm{~m} / \mathrm{s}$, is the circumferential velocity of the sealing tooth, and $N$ is the number of revolutions until leakage. Substituting the $n-t$ relation with the $v-N$ relation is simple, as all tests were performed using sealing sleeves of the same nominal diameter, equal to $50 \mathrm{~mm}$, and each test was performed for constant rotational speed. Moreover, describing the seal durability as the limiting surface, in the way shown Fig. 5, required introducing the water pressure $p$, which was kept constant in each individual test. Finally, the proposed seal durability model is the function of two variables and has the following form:

$$
v=f(x, y), \text { where: } x=\log (N), y=p
$$


The KT_MF relation which describes MF seal durability changes with the aid of function (1) takes the form:

$$
\begin{gathered}
v(x, y)=\frac{a}{x^{b}}+c * x^{d} * y \\
a=\left(v_{G}^{m} N_{0}\right)^{1 / m}, \quad b=\frac{1}{m}
\end{gathered}
$$

where: $v(x, y)$ is the seal velocity corresponding to durability $N$ at water pressure $p$,

$v_{G} \quad$ - boundary velocity of the seal,

$N_{0} \quad$ - number of seal revolutions corresponding to the boundary velocity,

$M \quad$ - slope of KT_MF characteristic for critical pressure $\mathrm{p} \rightarrow 0$,

The quantities $m, v_{G}$, and $N_{0}$ can be considered material constants for KZ_MF, while $c$ and $d$ are coefficient of the function $v=f(\log (N), p)$ and are different for different magnetic fluids. The exact value of the boundary velocity, $v_{G}$ cannot be precisely determined at this research stage (see Figs. 2, $3,4)$, which makes determining $m$ and $N_{0}$ difficult as well. This is why Equation (2) contains coefficients a and b (3) in an aggregated form which takes into account the effect of $m$, $v_{G}, N_{0}$ on the function $\mathrm{v}=f(\log (N), p)$.

\section{APPLYING THE DURABILITY MODEL TO EXPERIMENTAL DATA PROCESSING}

Within the framework of the planned research, more than 60 experimental test runs were performed. The time duration of an individual test ranged from slightly more than ten seconds to over 30 hours of continuous work. The rotational speeds of the seal which were set in these tests ranged from $1 \mathrm{rev} / \mathrm{s}$ to100 rev/s, at different water environment pressures which ranged between 0,023 $\mathrm{MPa}$ and 0,174 $\mathrm{MPa}$. These parameters were kept constant during each individual test run.

\begin{tabular}{|c|c|c|c|}
\hline $\begin{array}{l}\text { Fluid } \\
\text { FLA 002.25 }\end{array}$ & 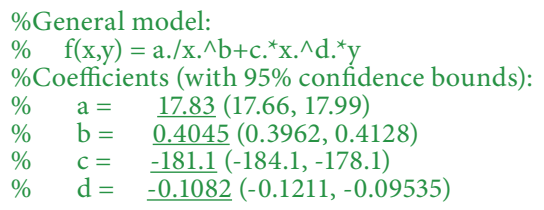 & $\begin{array}{l}\text { \%Goodness of fit: } \\
\% \text { SSE: } 6997 \\
\% \text { R-square: } 0.9277 \\
\% \text { Adjusted R-square: } 0.9277 \\
\% \\
\text { RMSE: } 0.8366\end{array}$ & (4) \\
\hline $\begin{array}{l}\text { Fluid } \\
\text { FLS_040_040 }\end{array}$ & 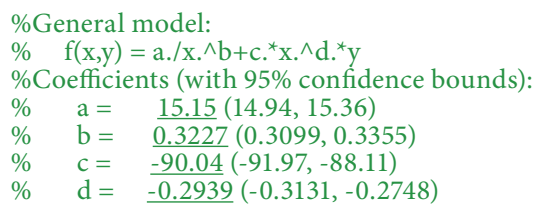 & $\begin{array}{l}\text { \%Goodness of fit: } \\
\% \text { SSE: } 286.6 \\
\% \text { R-square: } 0.9633 \\
\% \text { Adjusted R-square: } 0.9632 \\
\% \\
\text { RMSE: } 0.4238\end{array}$ & (6) \\
\hline
\end{tabular}

Tab. 2. Equation (2) coefficients
The durability model described in Section 2 was tested using $a, b, c$ and $d$ of Equation (2), calculated for different magnetic fluids. For each fluid, three values of these coefficients were calculated, but the surface diagrams $v=f[\log (N), p]$ shown in Figs. 7, 10 and 13 for particular fluids were created using the first (underlined) set of values from Table 2.

The figures below show durability surface diagrams for the examined seal with magnetic fluids (KT_MF - magnetic fluid durability curve), created using the function $v=f(\log (N), p)$ for three types of magnetic fluids used in the tests. Figures 6, 9 and 12 present diagrams obtained using experimental data, while Figs. 7, 10 and 13 show corresponding surfaces calculated using the relation (2) and values of coefficients $a, b$, $c$ and $d$ taken from Table 2. Figures 8,11 and 14 compare the diagrams obtained from the experiment and the relation (2).

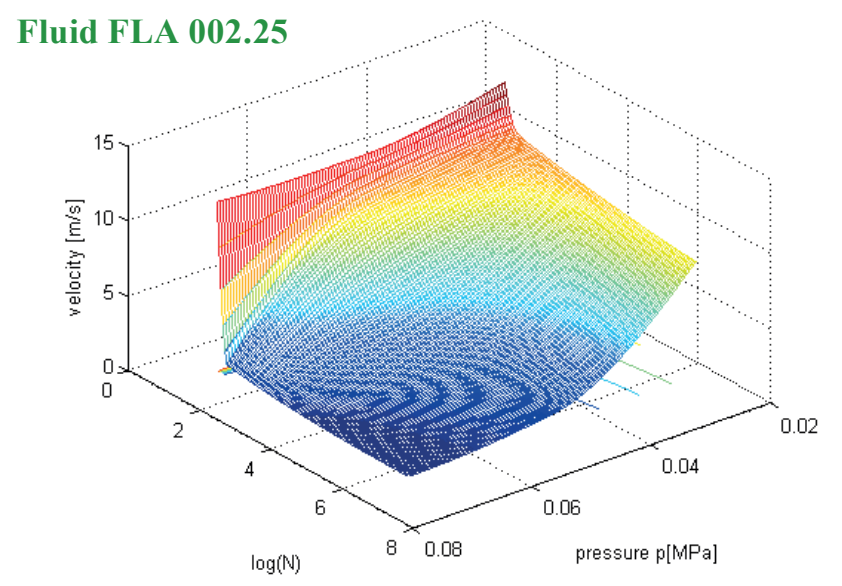

Fig.6. Experimental relation between the number of revolutions $N$ until leakage and the circumferential velocity $v$ of the seal, for different water environment pressures $p$. The number of revolutions shown in the $\log N$ form. Magnetic fluid in the seal: FLA 002.25[5]. the recorded experimental results. Table 2 collates coefficients 


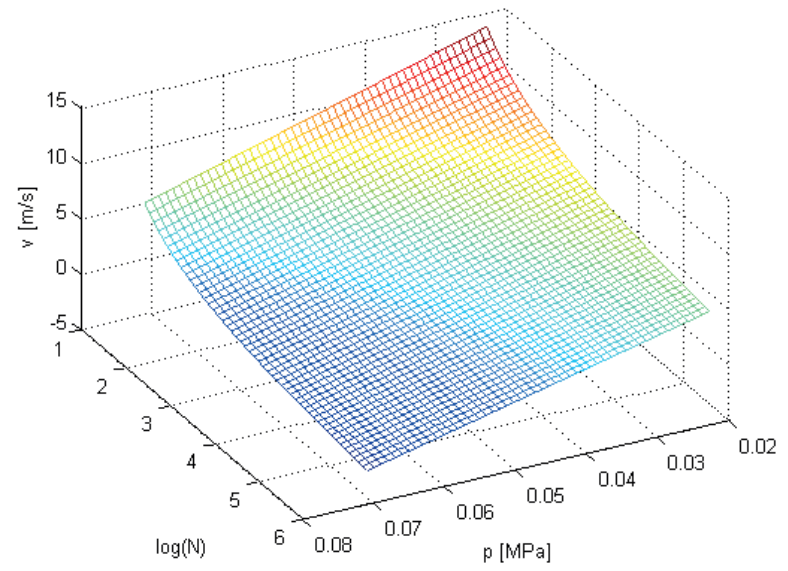

Fig.7. Theoretical relation $v=f(\log (N), p)$ acc. to formula (2), where: $v$ - circumferential velocity in the seal, $p$ - the set test pressure, $N$ - number of revolutions until leakage. Seal with fluid FLA 002.25, values of coefficients $a, b, c$ and $d$ from Table 2, set (4).

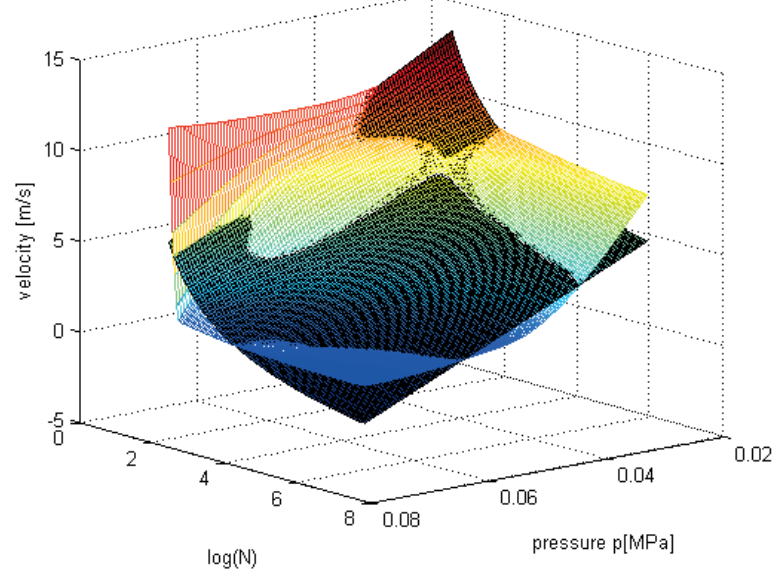

Fig.8. Comparing theoretical and experimental relation $v=f(\log (N), p)$, where: $v$ - circumferential velocity in the seal, $p$ - the set test pressure, $N$ - number of revolutions until leakage. Seal with fluid FLA 002.25.

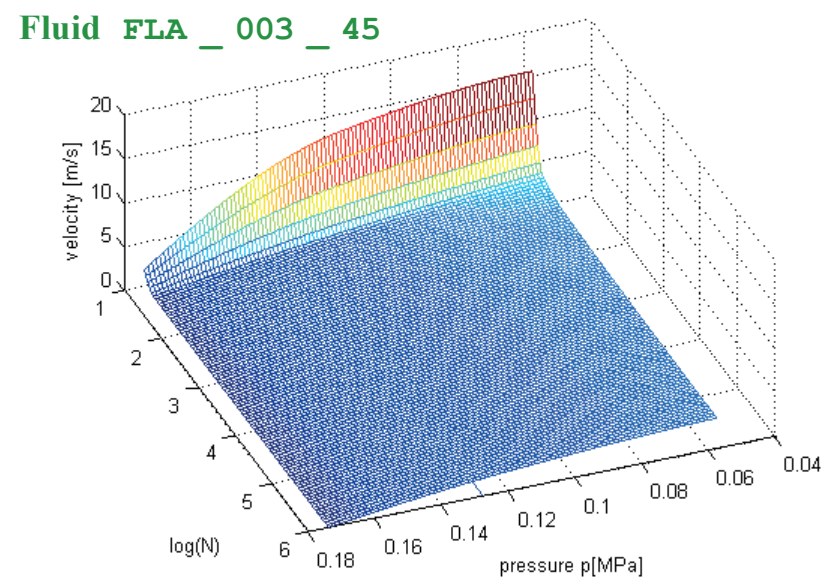

Fig. 9 Experimental relation between the number of revolutions $N$ until leakage and the circumferential velocity $v$ of the seal, for different water environment pressures $p$. The number of revolutions shown in the logN form. Magnetic fluid in the seal: FLA 003.45 [5].

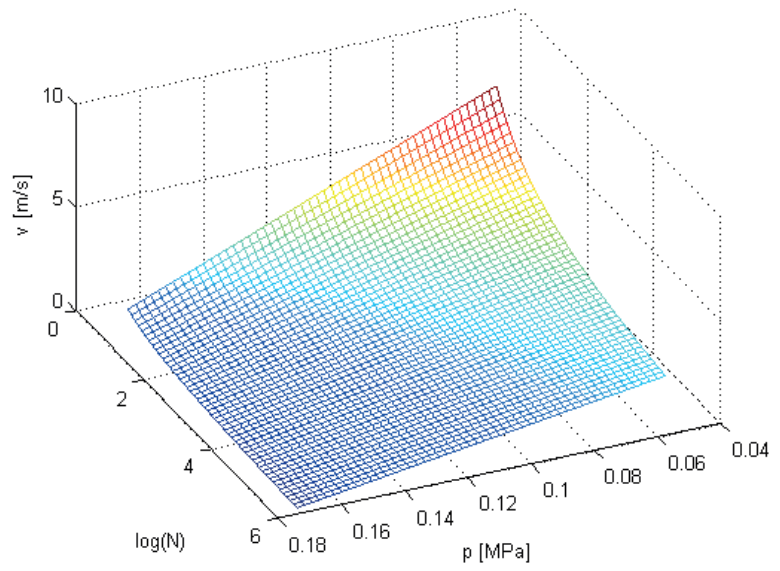

Fig.10. Theoretical relation $v=f(\log (N), p)$ acc. to formula (2), where: $v-$ circumferential velocity in the seal, $p$ - the set test pressure, $N$-number of revolutions until leakage. Seal with fluid FLA 003.45, values of coefficients $a, b, c$ and $d$ from Table 2, set (5).

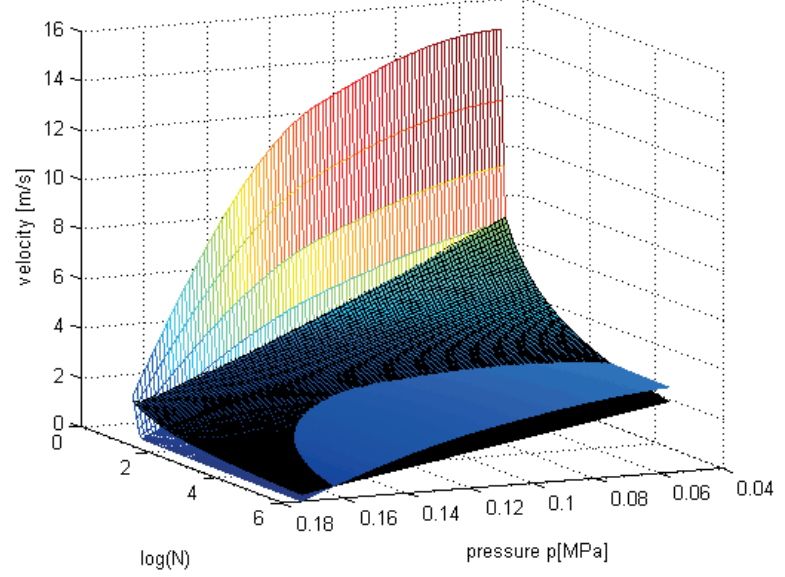

Fig.11. Comparing theoretical and experimental relation $v=f(\log (N), p)$, where: $v$ - circumferential velocity in the seal, $p$ - the set test pressure, $N$ - number of revolutions until leakage. Seal with fluid FLA 003.45.

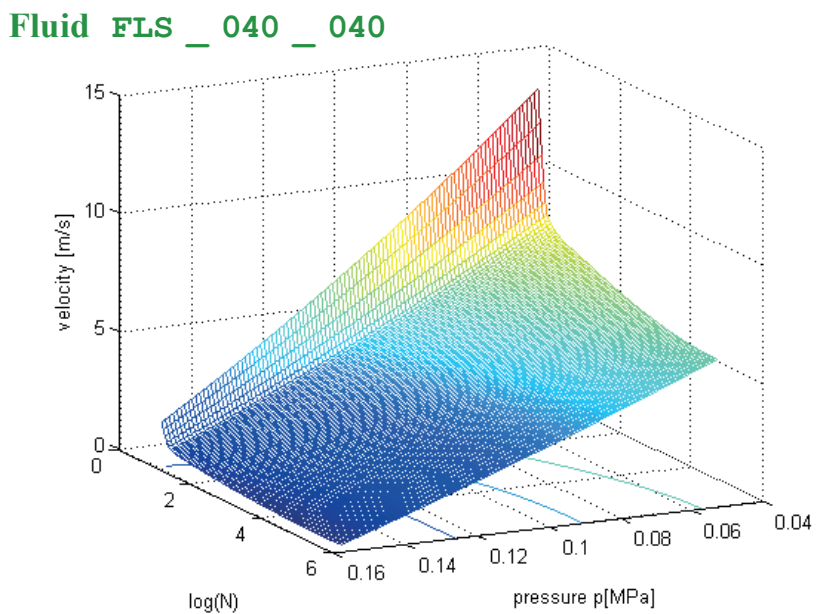

Fig.12.Experimental relation between the number of revolutions $N$ until leakage and the circumferential velocity $v$ of the seal, for different water environment pressures $p$. The number of revolutions shown in the $\log N$ form. Magnetic fluid in the seal: FLS040.040 [5]. 


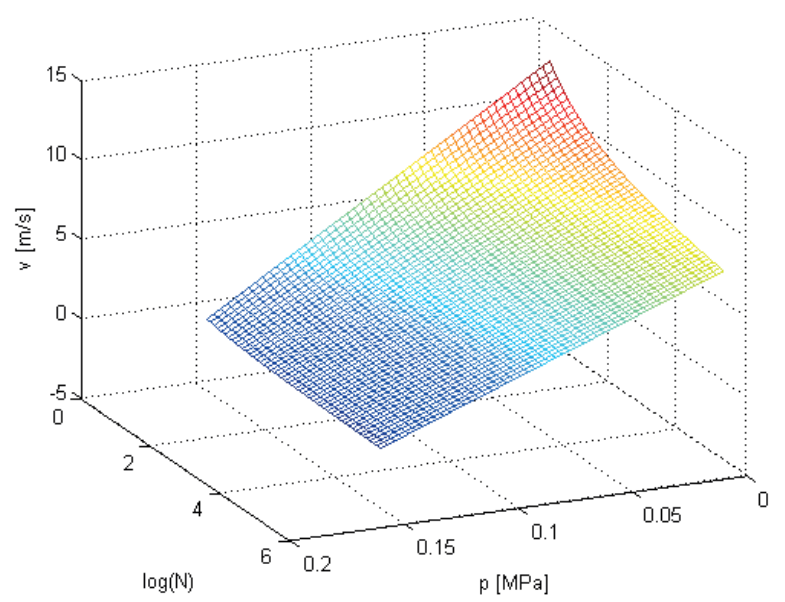

Fig.13. Theoretical relation $v=f(\log (N), p)$ acc. to formula (2), where: $v-$ circumferential velocity in the seal, $p$ - the set test pressure, $N$-number of revolutions until leakage. Seal with fluid FLS 040.040, values of coefficients $a, b, c$ and $d$ from Table 2, set (6).

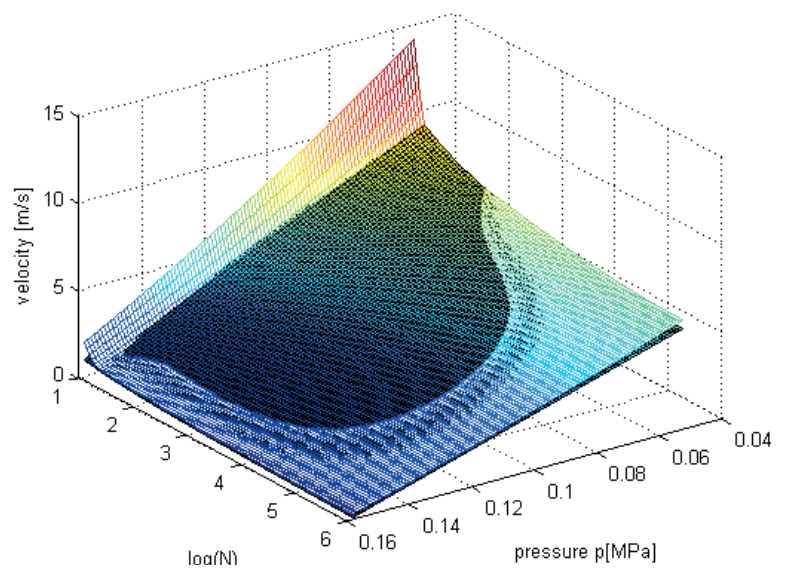

Fig.14. Comparing theoretical and experimental relation $v=f(\log (N), p)$, where: $v$ - circumferential velocity in the seal, $p$ - the set test pressure, $N$-number of revolutions until leakage. Seal with fluid FLS040.040.

\section{REMARKS AND CONCLUSIONS}

Summing up the results of the experimental research and theoretical analyses based on the developed seal durability model, we can conclude that:

1. The majority of tests reveal regular distribution of magnetic fluid velocity in the seal (circumferential velocity $v$ or rotational speed $n$ ) as the function of seal durability (number of revolutions $N$ or operating time $t$ until leakage) for different operating pressures $p(v=f(N, p)$. A characteristic feature of this distribution is the occurrence of the low durability interval (for high velocities of fluid motion) and the high durability interval (for low velocities), separated by the transitional interval in which the boundary velocity is situated.
2. The surface diagrams shown in Figs. 8, 11 and 14 reveal that the results of experimental examination $v[\log (N), p]$ and theoretical analysis $v[\log (N), p]$ presented in the form of relation (2) are similar to each other over large part of the examined parameters. Larger differences in velocity $v=f[\log (N), p]$ between the experiment and theory can be observed for higher $\log (N)$ values, where they amount to $1-2 \mathrm{~m} / \mathrm{s}$, while in the area of rapid increase of the $v$ function they are nearly twice as large.

3. Based on the analysis of diagrams shown in Figs.7, 10 and 13 , we can conclude that the seal durability model in the form of $v[\log (N), p]$, written as relation (2) based on relation (1), correctly describes the increasing trend in the number of revolutions $N$ until leakage as a function of the decreasing velocity $v$ for different pressures $\mathrm{p}$.

4. A serious problem at the present research stage is the inability to determine precisely the values of the boundary velocity $v_{G}$ and limiting durability $N_{0}$. Correct values of these quantities would make it possible to calculate the slope $m$ in relation (3) and replace coefficients $a$ and $b$ in relation (2) with real values. The present approach to this problem which introduces the term of "boundary velocity area" is highly unsatisfactory.

5. Further examination of durability of seals with magnetic fluids operating in water environment is necessary, in particular in the velocity boundary area, to gain more information on this issue and provide opportunities for more precise calculation of the velocity boundary value.

\section{BIBLIOGRAPHY}

1. Bielański J.: Description of the hydrodynamic pressure field function around the ship hull, Hydroacoustics, Vol.14, pp. 17-22, Gdynia 2011. 208

2. Ferrolabs, Inc. • Sterling, VA United States, http://www. ferrolabs.com/. 2010, company catalogue.

3. GASIAK, G., PAWLICZEK, R.: Fatigue strength of structural steel in non-symmetrical load conditions (in Polish). Zeszyty Naukowe Mechanika, Opole University of Technology, Vol. 74, pp., 25-41, Opole 2002.

4. Guo, C., Feng, S.: Sealing mechanism of magnetic fluids. Journal of Shanghai University (English Edition), 2006, 10(6), pp.522-525.

5. Liu, T., Cheng, Y., Yang, Z.: Design optimization of seal structure for sealing liquid by magnetic fluids. Journal of Magnetism and Magnetic Materials, Vol: 289, Complete, March 2005.

6. Matuszewski, L.: Procedure for determining durability and results of experimental tests of multi-tooth MF seals operating in water (in Polish). PB, Department of 
Machine Design and Technology, AGH, Cracow 2012. 211, Zeszyty Naukowe AGH

7. Matuszewski, L.: Final report on the research project $\mathrm{R}$ 00-O0017/3 entitled: Implementation prototype of electric annular propulsion system equipped with magnetic bearings and sealed with magnetic fluids - structure and operating tests (in Polish).

8. Mitamura, Y., Arioka, S., Sakota, K., Azegami, M.: Application of a magnetic fluid seal to rotary blood pumps., J. Phys.: Condens. Matter 20 (2008) 204145 (5pp).

9. Odenbach, S: Magnetoviscous effects in magnetic fluids, Berlin; Heidelberg; New York; Barcelona; Hong Kong; London; Milan; Paris; Tokyo: Springer, 2002, (Lecture notes in physics: N.s. M, Monographs; 71)

10. Odenbach, S. (Ed.): Colloidal Magnetic Fluids: Basics, Development and Application of Magnetic fluids, Lect. Notes Phys. 763 (Springer, Berlin Heidelberg 2009), DOI 10.1007/978-3-540-85387-9

11. Orlov, D.W., Mikhalev, Y.O., Myshkin, N.K., Podgorkov, W.W., Sizov, A.P.: Magnitnye żidkosti w mashinostroenii. Mashinostroenie, Moskva 1993.

12. P.P.H.U. “ENES” Pawel Zientek, Warszawa, www.magnesy.pl/, company catalogue.

13. Research project: Theoretical analysis, structure and experimental tests of seals with magnetic fluids used in sealing systems operating in water environment - in the aspect of operating condition limits; final report (in Polish), AGH, KKiEM, 2010.

14. Rosensweig, R.E.: Ferrohydrodynamics. Dover Publications, Inc. Mineola, New York, 1997

15. SALWIŃSKI, J., HORAK, W., SZCZECH, M., KOWALIK, G.: Analysis of design issues concerning magnetic fluid seals working in reciprocating motion conditions (in Polish), XXVII Symposium on machinery design fundamentals: Zakopane 2007, 22-26 Sept.

16. Szydło, Z., Matuszewski, L.: Experimental research on effectiveness of the magnetic fluid seals for rotary shafts working in water. Polish Maritime Research, 2007, vol. 14, no. 4 , pp. $53-58$.

17. Szydło, Z., Matuszewski, L.: Ring thruster - a preliminary optimisation study of magnetic fluid seal and propeller. Polish Maritime Research, 2007, special issue S1,pp. 71-74.

18. Szydło, Z., Matuszewski, L.: The application of magnetic fluids in sealing nodes designed for operation in difficult conditions and in machines used in sea environment. Polish Maritime Research, 2008, vol. 15, no. 3, pp. 49-58.

\section{CONTACT WITH THE AUTHOR}

\author{
Leszek Matuszewski \\ e-mail:leszekma@pg.gda.pl \\ Gdansk University of Technology \\ Narutowicza 11/12 \\ 80-233 Gdansk \\ Poland
}

